reaction a technical white oil was used as diluent. The product boiling between $98^{\circ}$ and $101^{\circ} \mathrm{C}$., $750 \mathrm{~mm}$. was obtained in a 33 per cent yield; its physical constants were:

$$
n_{D}^{19^{\circ} \mathrm{C} .}=1 \cdot 4093, D_{4^{\circ} \mathrm{C} .}^{25^{\circ} \mathrm{C} .}=0 \cdot 727 .
$$

The knock-rating of the hydrocarbon was determined in the 'Ethyl Gasoline S.30' (modified Delco) testing unit in a 20 per cent volume blend with a standard spirit, the engine jacket temperature being $100^{\circ} \mathrm{C}$. The blending octane number of the heptine-1 was found to be $79 \cdot 5$.

It is of interest to record the knock-rating of this hydrocarbon together with representative hydrocarbons of seven-carbon atoms of other series, each being rated on the $n$-heptane $=0$, iso-octane $(2 \cdot 2 \cdot 4$ trimethylpentane) $=100$, standard :

Hydrocarbon.

$\begin{array}{cc}\text { Heptine-1 } & \text { of } 100^{\circ} \cdot \mathrm{C}^{\circ} \\ \text { Heptene-1 } & 79 \cdot 5 \\ \text { Heptene-3 } & 59 \cdot 5 \\ \text { n-Heptane } & 113 \cdot 5 \\ \text { Ethylcyclopentane } & 0 \\ \text { Methylcyclohexane } & 57 \\ \text { Cycloheptane } & 75 \\ \text { 1-Ethylcyclopentene } & 26 \cdot 5^{*} \\ \text { 1-Methylcyclohexene } & 101 \cdot 5^{*} \\ \text { Toluene } & 132 \cdot 5^{*} \\ \text { *Lovell, Campbell and Boyd (see }{ }^{1} \text { ). }\end{array}$

It is thus apparent that the introduction of a double bond into the heptane molecule in the $\alpha$ position increases the blending octane number considerably, and that the introduction of a treble bond in the same position further increases this value though not to so great an extent.

A. R. Bowen.

A. W. NAsh.

Oil Engineering and Refining Department, University of Birmingham.

F. H. Garner.

Anglo-American Oil Co., Ltd.,

83, Albert Embankment, London, S.E.11.

1 World Petroleum Congress, London, 1933.

2 Bull. Soc. Chim., 35, 481; 1924

Ann. Chim., 3, 191, 325; 1925.

\section{Pleochroism and Birefringence in Crystals}

Prof. W. L. BragG ${ }^{1}$ explains the strong birefringence of some carbonates and nitrates as being due to the interaction of the optical dipoles induced in the component atoms. For example, X-ray analysis shows that the carbonate ions in calcite have a plane structure, their planes being perpendicular to the optic axis of the crystal. With this arrangement, the interaction of the dipoles results in a much smaller refractivity for vibrations along the optic axis than for perpendicular vibrations.

The effect of the interaction can also be regarded from a slightly different point of view. So far as observations in the visible and in the near ultraviolet regions are concerned, the effect would be equivalent to a change in the natural frequencies of the ions; for the nitrate, carbonate and similar ions, the natural ultra-violet frequencies will be increased for vibrations along their axes, while for perpendicular vibrations the natural frequencies will be diminished. The smaller refractivity for the former vibrations than for the latter, follows then as a natural consequence.

On this view we should expect, as wo proceed from the visible region towards the ultra-violet, the absorption of these ions to begin earlier for vibrations perpendicular to the axis than for vibrations along the axis. That this is actually so for the nitrate ion was shown in a previous communication ${ }^{2}$. We have now studied the absorption of several other crystals, namely, calcite, dolomite and ankerite, which are uniaxial, and aragonite and potassium chlorate, which are approximately so. They all show pleo. chroism in the ultra-violet, which grows stronger with decreasing wave-length, the vibrations along their optic axes being less absorbed than the perpendicular vibrations.

In strong contrast with these crystals are anhydrite, celestite, barite and selenite, which show practically no pleochroism; as is well known, the birefringence of these crystals is very feeble.

\section{K. S. KRISHNAN.}

B. MukHopadhyay.

210 Bowbazar Street, Calcutta.

June 30 .

${ }^{1}$ Proc. Roy. Soc., A., 105, 370 ; 1924.

2 NATURE, 128, 12, July 5, 1930.

\section{Integral Right-angled Triangles}

The series of series of $a^{2}+b^{2}=c^{2}$ in integral numbers does not seem to be familiar to mathematical friends, so it may be worth stating the foundation of the system.

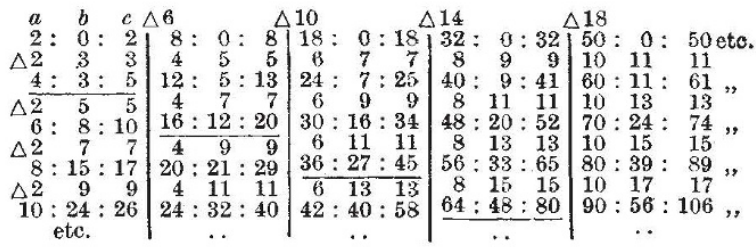

The usual $3: 4: 5$ begins here as $4: 3: 5$, underlined to catch the eye. Carried further, at the 14th rank we reach 336:377:505 for instance. There are nineteen such triangles without requiring three figures.

Flinders Pfitrie.

\section{The Rise of the Himalaya}

MR. L. R. WAGER, in his interesting letter rogarding the rise of the Himalaya ${ }^{1}$, ranges himself on the side of those who believe that the outer ranges of the Himalaya are in isostatic adjustment.

Gravity data seem to be opposed to this view. Since gravity is in excess at Simla, Chakrata, Mussoorie, Lansdowne, Ranikhet, Sundakphu and Darjeeling, recent uplifts of these parts, so far from favouring isostatic adjustment, have been diametrically opposed to it.

Geodetic Branch,

E. A. Glennnte.

Survey of India,

Dehra Dun.

Aug. 3.

1 Nature, 132, 28, July 1, 1933. 